\title{
SADIA S.A. E PERDIGÃO S.A.: análise da trajetória histórica e do desempenho que antecederam o seu processo de fusão
}

\section{1- Marines Taffarel \\ Universidade Estadual do Centro Oeste - UNICENTRO marinestaffarel@yahoo.com.br}

\author{
3- Willson Gerigk \\ Universidade Estadual do Centro Oeste - UNICENTRO \\ gerigkw@yahoo.com.br
}

\author{
2- Paulo Mello Garcias \\ Universidade Federal do Paraná - UFPR \\ paulomg@ufpr.br
}

\section{RESUMO}

O estudo tem por objetivo analisar comparativamente a trajetória histórica de crescimento, sob a ótica do processo de aquisições e diversificações internas, das agroindústrias Sadia S.A e Perdigão S.A, bem como, o desempenho das empresas no período de 1997 a 2008. A metodologia caracteriza-se como descritiva, bibliográfica e documental com abordagem qualitativa e quantitativa das informações. Para a análise da evolução real econômico-financeira deflacionou-se os dados das empresas aplicando-se o Índice Geral de Preços de Disponibilidade Interna (IGP-DI) da Fundação Getulio Vargas, comparando-se a evolução da receita bruta obtida no mercado externo e interno, lucro líquido, ativo total e número de funcionários das empresas, juntamente com o desempenho medido por indicadores contábilfinanceiros. Os resultados demonstram que a Sadia e a Perdigão apresentam trajetórias de crescimento semelhantes. A análise de desempenho confirma a grande competitividade entre as duas empresas que termina com a fusão do grupo em maio de 2009.

\section{Palavras-Chave}

Trajetória de Crescimento. Diversificação Interna. Análise de Desempenho. Agroindústrias Sadia S.A e Perdigão S.A.

\begin{abstract}
The study has the objective to analyze comparatively the historical increase, in accordance to the view of the process of acquisitions and internal diversifications of Sadia S.A. and Perdigão S.A. agribusinesses as their performance in the period from 1997 to 2008. The methodology is characterized as descriptive, bibliographical and documental with qualitative and quantitative approach of the information. For the analysis of the real economic-financial evolution it was deflated the data of the companies applying the General Index on Prices of Available Interns (IGP-DI) of Getulio Vargas Foundation, comparing the income evolution obtained at the external and internal market, net income, total assets and number of employees of the companies, together with the measured performance for accounting and financial indicators. The results demonstrate that Sadia S.A and Perdigão S.A companies present similar historical increase. The analysis of performance confirms the great competition between the two companies whom it finishes with the fusion group in May of 2009.
\end{abstract}

\section{Keywords}

Historical increase. Internal Diversification. Performance of Analysis. Sadia S.A. and Perdigão S.A. agribusinesses. 


\section{Introdução}

As decisões que envolvem o ambiente corporativo apresentam como base as estratégias das empresas, tanto de operacionalidade, quanto de crescimento, definidas entre outros fatores, pela competitividade do mercado.

As agroindústrias Sadia S.A. e Perdigão S.A., consideradas as maiores indústrias do setor carnes e derivados do Brasil, reservam um ambiente particular de competitividade histórica, que acompanharam a trajetória dessas empresas por mais de meio século. Contudo, no dia 19 de maio de 2009, foi anunciada a fusão das duas companhias, e, por conseqüência, a criação da Brasil Foods S.A. (BRF), que nasce como uma das maiores empresas brasileiras.

A fusão entre a Sadia S.A. e a Perdigão S.A., é um fato histórico para o Brasil, não somente pela importância econômica, mas também, pela rivalidade que acompanhou a trajetória das empresas. Seus históricos apresentam várias similaridades, como: processo de formação e crescimento, diversificação de produtos, parcerias com produtores rurais, busca pelo mercado exterior, incorporações de empresas e diversificações internas.

Com a finalidade de melhor conhecer o histórico de crescimento e desempenho da Sadia S.A. e da Perdigão S.A., a pesquisa busca responder 0 seguinte questionamento: Como se compara o processo de crescimento das agroindústrias Sadia S.A. e Perdigão S.A., e qual o desempenho dessas empresas no período que antecedeu o seu processo de fusão?

O objetivo da pesquisa, é apresentar o processo de formação e crescimento da Sadia S.A. e da Perdigão S.A., assim como os seus desempenhos, no período que antecedeu o processo de fusão dos grupos.

O trabalho é composto de cinco seções. Após esta introdução, o referencial teórico é brevemente apresentado, juntamente com o comparativo histórico das empresas estudadas. A terceira seção contempla a metodologia. Na quarta seção, os resultados da pesquisa empírica são mostrados e analisados, e, por fim, são apontadas as considerações finais da pesquisa.

\section{Referencial Teórico}

Nesta seção, a análise da trajetória histórica da Sadia S.A. e Perdigão S.A. é contextualizada por meio das aquisições e diversificações internas, utilizando como referência, as obras de Penrose
(1959), que visa identificar a potencialidade interna de crescimento da firma, e Chandler (1990), que analisa como ocorrem as transformações das organizações e como estas facilitaram seu desenvolvimento.

\subsection{Formação e crescimento das empresas}

A análise da trajetória histórica desde a formação, crescimento e expansão da Sadia e Perdigão, passa pelo entendimento do que é uma empresa e suas perspectivas de avaliação. Penrose $(1959$, p. 3) define uma empresa como "[...] uma organização administrativa, com uma coleção de recursos produtivos, com o propósito de organizar o uso dos recursos próprios, junto com os recursos externos, para a produção e venda de produtos e serviços, com lucro".

Na visão de Chandler (1990, p. 15), a moderna empresa industrial pode ser definida como um conjunto de unidades operacionais, cada qual com suas instalações e seu quadro de pessoal, cuja totalidade de recursos e atividades é coordenada, monitorada e alocada por uma hierarquia de executivos de segunda e primeira linhas. $\mathrm{O}$ autor relata que somente a existência e a capacidade dessa hierarquia podem tornar as atividades e as operações de toda a empresa, algo maior que a mera soma de suas atividades.

$\mathrm{Na}$ busca de uma estratégia expansionista, as empresas podem executar atividades individuais ou simultâneas, como construir ou adquirir instalações, comprar ou realizar fusões com outras empresas. Esses processos permitem a manutenção das taxas de retornos no longo prazo e reduzem os custos globais de produção, entre outros fatores. A redução de custos e o uso eficiente dos recursos resultam em economias de escala, na produção e distribuição, além de economias de escopo ou redução dos custos das transações (CHANDLER, 1990).

Atingido os investimentos necessários à produção, distribuição e criada a indispensável hierarquia gerencial, a empresa industrial cresce e incorpora novas unidades. Segundo Chandler (1990, p. 36-37) este fato de quatro maneiras: 1) Adquirindo ou juntando-se a empresas que utilizassem os mesmos processos para fabricar produtos semelhantes, para os mesmos mercados - crescimento por associações horizontais; 2) Incorporando unidades empenhadas numa etapa anterior ou posterior do processo de fabricação de um produto, desde a extração ou transformação da matéria-prima até a montagem ou embalagem final - crescimento por integração vertical; 3) 
Expandindo geograficamente; 4) Aproveitando as tecnologias ou os mercados de que a empresa possui para criar novos produtos.

Quanto à diversificação de atividades, Penrose (1959) explica que isto ocorre quando uma empresa passa a produzir novos produtos, incluindo os intermediários, sem excluir suas linhas antigas de produção. A autora descreve que o crescimento da firma depende de seus serviços empreendedores, associados à necessidade de criação de demandas superiores às que são oferecidas de maneira natural pelo mercado. Este fato pode ser observado no processo de diversificação das empresas Sadia S.A e Perdigão S.A, que ao buscarem expandir os seus mercados por intermédio do desenvolvimento de novos produtos passaram a utilizar de bases tecnológicas diferenciadas.

Dalla Costa (2007) menciona que, de forma geral, o desenvolvimento industrial, e a complexidade que envolveu esse processo, fez com que as tradicionais empresas familiares fossem substituídas por uma moderna empresa industrial. $\mathrm{Na}$ empresa familiar tradicional, os proprietários eram os próprios dirigentes, com o crescimento das empresas, diversificação e profissionalização dos seus quadros, surgiu à necessidade de separação entre a propriedade e gestão, visando à estabilidade e continuidade das atividades empresariais.

O processo de crescimento, verificado por Penrose (1959) e Chandler (1990), pode ser percebido nas agroindústrias Sadia S.A. e Perdigão S.A., que buscaram expandir seus ativos por meio de processos de aquisições ou fusões com outras empresas, diversificação de produção, reorganizações internas, especialização no segmento de carnes e derivados e, por fim, a fusão, entre os dois grupos, em maio de 2009.

\subsection{Sadia S.A. e Perdigão S.A.: Formação e Crescimento}

O processo de formação e crescimento da Sadia S.A. e da Perdigão S.A. reservam várias similaridades. Com a finalidade de comparar o processo de crescimento e diversificação de produção das empresas, no Quadro 1 apresenta-se um comparativo histórico das agroindústrias em estudo.

Assim como descrito por Chandler (1990), percebe-se que a trajetória expansionista da Sadia S.A. e da Perdigão S.A. foram consolidadas em atividades individuais e simultâneas, construção ou aquisições de instalações, bem como, nos processos de aquisições e fusões com outras empresas. Os processos de diversificações das empresas, relatados por Penrose (1959) podem também ser observados na Sadia S.A. e na Perdigão S.A., tendo em vista que as empresas buscaram expandir seus mercados por intermédio da diversificação e lançamento de novos produtos.

Contudo, a Sadia sempre esteve focada no segmento alimentício, mais especificamente no setor de carnes e derivados. A Perdigão, embora atualmente tenha suas atividades centralizadas no setor alimentício, mais especificamente no setor de carnes e derivados, não o fez nas primeiras décadas de sua existência. A empresa investiu em vários segmentos expandindo suas atividades de forma não centrada.

\begin{tabular}{|c|c|c|}
\hline PERÍODO & PERDIGÃO S.A. & SADIA S.A. \\
\hline $\begin{array}{l}\text { Décadas de } 40 \\
\text { e } 50\end{array}$ & $\begin{array}{l}\text { Fundada em 1939, com um abatedouro de suínos na } \\
\text { cidade de Videira, estado de Santa Catarina. Em } 1943 \\
\text { passa a diversificar suas atividades com a aquisição de } \\
\text { curtume, processando também pele suína. No ano de } \\
\text { 1945, constitui-se em sociedade anônima e começa a } \\
\text { atuar no setor madeireiro. }\end{array}$ & $\begin{array}{l}\text { Fundada em 1944, inicia suas atividades em } \\
\text { Concórdia, estado de Santa Catarina, a partir da } \\
\text { aquisição de um frigorífico em dificuldades. No início } \\
\text { de suas atividades, explora os subprodutos da carne } \\
\text { suína e busca canais de distribuição, primeiramente, } \\
\text { no estado de São Paulo. }\end{array}$ \\
\hline $\begin{array}{l}\text { Décadas de } 60 \\
\text { e } 70\end{array}$ & $\begin{array}{l}\text { Mantém suas atividades industriais no estado de Santa } \\
\text { Catarina e busca expandir a comercialização de seus } \\
\text { produtos em São Paulo. Potencializa suas atividades de } \\
\text { curtume, após adquirir uma empresa da área. Investe, } \\
\text { ainda, em um hotel, supermercado, cultivo de maçãs, } \\
\text { fabricação de ração animal, industrialização de soja e } \\
\text { derivados, além de constituir abatedouro exclusivo de } \\
\text { aves, passando a exportar esse tipo de carne para a } \\
\text { Arábia Saudita. }\end{array}$ & $\begin{array}{l}\text { Início de parcerias com produtores rurais para a } \\
\text { produção de suínos. Aumenta o número de granjas } \\
\text { integradas de frangos e inicia o seu processo de } \\
\text { diversificação de produtos, lançando produtos semi- } \\
\text { prontos e investe ainda no negócio da soja. Realiza } \\
\text { os seus primeiros contratos de exportação e constitui } \\
\text { canais de distribuição praticamente em todo mercado } \\
\text { brasileiro. Busca consolidar-se no mercado } \\
\text { internacional, principalmente nos países do Oriente } \\
\text { Médio, Europa e Estados Unidos. Em 1971, realiza } \\
\text { processo de abertura de seu capital. }\end{array}$ \\
\hline
\end{tabular}




\begin{tabular}{|c|c|c|}
\hline PERÍODO & PERDIGÃO S.A. & SADIA S.A. \\
\hline Décadas de 80 & $\begin{array}{l}\text { Realiza o processo de abertura de capital, passando a } \\
\text { negociá-lo, em 1981, na Bolsa de Valores. Busca } \\
\text { expandir suas atividades, adquirindo e constituído novas } \\
\text { indústrias do ramo agropecuário e frigorífico, } \\
\text { especialmente fora do estado de Santa Catarina. } \\
\text { Investe na diversificação de produtos lança a linha } \\
\text { Chester. Inicia em } 1986 \text { o abate de bovinos, com novos } \\
\text { produtos congelados de pratos prontos. Busca } \\
\text { fortalecer-se no mercado europeu, realizando no final da } \\
\text { década de } 80 \text { parcerias com empresa japonesa para a } \\
\text { exportação de carnes. }\end{array}$ & $\begin{array}{l}\text { Inaugura unidades de processamento de soja no } \\
\text { Paraná e no Mato Grosso, além, de abatedouros de } \\
\text { suínos e bovinos em diversos estados brasileiros. No } \\
\text { final desta década a empresa era considerada uma } \\
\text { das maiores exportadoras do país e comercializava } \\
\text { os seus produtos para } 40 \text { países. Em } 1989 \text { morre seu } \\
\text { fundador Attilio Francisco Xavier Fontana, } \\
\text { considerado um dos grandes empreendedores do } \\
\text { século XX. }\end{array}$ \\
\hline Década de 90 & $\begin{array}{l}\text { Realiza reorganização de suas atividades, focando-se } \\
\text { na sua atividade principal. Com o falecimento de seus } \\
\text { fundadores no início da década de } 90 \text {, a terceira } \\
\text { geração da Família fundadora da Perdigão teve sua } \\
\text { presidência perdida para os acionistas minoritários da } \\
\text { empresa. Em 1994, a Perdigão realiza o processo de } \\
\text { transferência acionária das ações da família Brandalise } \\
\text { para um pool de fundos de pensão. A empresa busca a } \\
\text { partir de então, uma gestão mais profissionalizada, por } \\
\text { intermédio de reestruturações societárias e } \\
\text { organizacionais. }\end{array}$ & $\begin{array}{l}\text { Implanta o sistema de gestão e operação pela } \\
\text { qualidade total e abre diversas filiais comerciais em } \\
\text { Tóquio, Milão e Buenos Aires. Inaugura sua fábrica } \\
\text { de hidrogenados, em Paranaguá - PR, marcando o } \\
\text { ingresso no segmento de margarinas. Encerra suas } \\
\text { atividades com bovinos e soja e especializa-se na } \\
\text { produção e distribuição de alimentos industrializados } \\
\text { congelados e resfriados. Realiza lançamento de } \\
\text { novos produtos, em especial os semi-prontos, prontos } \\
\text { congelados e de conveniência. Efetua sucessivas } \\
\text { incorporações e chega ao final dos anos } 90 \text { com um } \\
\text { parque fabril composto por } 12 \text { fábricas. }\end{array}$ \\
\hline De 2000 a 2008: & $\begin{array}{l}\text { Ganha destaque pela infra-estrutura de pessoal e } \\
\text { realiza a adesão ao Nível } 1 \text { de Governança Corporativa } \\
\text { da Bovespa. Adquire entre outros o Frigorífico Batavia e } \\
\text { efetua a manutenção da marca Batavo no mercado. } \\
\text { Busca maior internacionalização lança produtos } \\
\text { diferenciados e sobremesas. Inaugura novas unidades } \\
\text { de produção e logística de distribuição em Curitiba. No } \\
\text { ano de } 2006 \text {, estréia no Novo Mercado da Bovespa. Em } \\
2007 \text {, escolhida melhor empresa brasileira e a melhor } \\
\text { do setor de consumo e varejo da América Latina em } \\
\text { Governança Corporativa. Aquisição em } 2007 \text { do } \\
\text { frigorífico Mirassol D' Oeste, no Estado do Mato Grosso } \\
\text { e em } 2008 \text { adquire a Eleva. }\end{array}$ & $\begin{array}{l}\text { Busca maior competitividade no mercado interno e } \\
\text { maior atuação no mercado externo, com filiais na } \\
\text { Argentina, Uruguai e Chile. Escritórios comerciais e } \\
\text { de representação são abertos em países como a } \\
\text { Itália, Inglaterra, Emirados Árabes, Japão, Paraguai e } \\
\text { Bolívia. Realiza em } 2001 \text { a adesão ao Nível } 1 \text { de } \\
\text { Governança Corporativa na Bovespa e realiza o } \\
\text { lançamento de ADRs - American Depositary Receipts } \\
\text { na Bolsa de Nova York. Em } 2004 \text {, a Sadia inaugura } \\
\text { novos centros de distribuição e efetua a aquisição da } \\
\text { Só Frango Produtos Alimentícios. Em 2005, retoma o } \\
\text { processo de abate de bovinos para a comercialização } \\
\text { interna e externa. }\end{array}$ \\
\hline
\end{tabular}

O Quadro 2 sintetiza os principais eventos que caracterizaram a trajetória histórica das Agroindústrias Sadia S.A e Perdigão S.A.

Quadro 2 - Caracterização da Trajetória Histórica da Sadia S.A e da Perdigão S.A.

\begin{tabular}{|c|c|}
\hline PERÍODO & CARACTERIZAÇÃO DA TRAJETÓRIA HISTÓRICA \\
\hline Décadas de 40 e 50 & Período de formação das empresas \\
\hline Décadas de 60 e 70 & Período de Consolidação e Diversificação das empresas e internacionalização da Sadia \\
\hline Décadas de 80 & Diversificação territorial e de produtos da Perdigão e Expansão das atividades da Sadia \\
\hline Décadas de 90 & $\begin{array}{l}\text { Crise financeira e fim do Controle familiar da Perdigão; Sedimentação no mercado } \\
\text { internacional e Reestruturação estratégica da Sadia }\end{array}$ \\
\hline De 2000 a 2008: & $\begin{array}{l}\text { Diversificação e Internacionalização da Perdigão; Modernização e capacitação da gestão } \\
\text { Sadia }\end{array}$ \\
\hline 2009 & Fusão da Sadia S.A e Perdigão S.A com a criação da Brasil Foods S.A. (BRF) \\
\hline
\end{tabular}

FONTE: Os Autores (2009)

A análise do processo de crescimento das empresas requer reflexão e entendimento de sua base histórica. Ao analisar as empresas Sadia S.A. e Perdigão S.A., percebe-se estratégias diferenciadas no crescimento destes grupos. O Quadro 3 resume a evolução dos processos de aquisições, incorporações e ampliações de atividades das empresas. 
Quadro 3 - Comparativo das Principais Aquisições/Incorporações e Ampliação de Atividades

\begin{tabular}{|c|c|c|}
\hline PERÍODO & PERDIGÃO S.A. & SADIA S.A. \\
\hline 1939 a 1949 & $\begin{array}{l}\text { Fundada em } 1939 \text { com a aquisição de Frigorífico; } \\
\text { aquisição de curtume; Serrarias; construção de } \\
\text { moinho de trigo. }\end{array}$ & Fundada em 1944 com a aquisição de frigorífico. \\
\hline 1950 a 1959 & $\begin{array}{l}\text { Construção de Granjas; Expresso Perdigão; Fabrica } \\
\text { de Rações. }\end{array}$ & $\begin{array}{l}\text { Aquisição e Construção de moinhos; investimentos } \\
\text { em transportes aéreos }\end{array}$ \\
\hline 1960 a 1969 & Construção da Gráfica Perdigão Ltda. & $\begin{array}{l}\text { Aquisição da Sadia em Toledo; Construção da Sadia } \\
\text { Frigográs. }\end{array}$ \\
\hline 1970 a 1979 & $\begin{array}{l}\text { Construção de Hotel e Supermercado, Abatedouro } \\
\text { de Aves, Perdigão Agropecuária S.A e Fabrica de } \\
\text { óleo. Aquisição do Empório Couros S.A, da União } \\
\text { Velosence Frigorífico, Fazendas de maçãs, Rações } \\
\text { Pagnocelli S.A. }\end{array}$ & $\begin{array}{l}\text { Aquisição da Sadia Oeste, Desativação da Sadia } \\
\text { Transporte Aéreos, Construção da Sadia Avínicola, } \\
\text { Agropastoril Catarinense, Fabricas de esmagamento e } \\
\text { extração de óleo de soja em Toledo e em Dois } \\
\text { Vizinhos e em Joaçaba. }\end{array}$ \\
\hline 1980 a 1989 & $\begin{array}{l}\text { Aquisição da Agropecuária Confiança Ltda., } \\
\text { Comércio Indústria Saule Pagnocelli S.A., Reunidas } \\
\text { Ouro S.A., Reflora, Nodarisa S.A., Suely Avícola } \\
\text { S.A., Suley Rações S.A., Frigorífico Cantagalo S.A, } \\
\text { Frigorico, Agropastoril, Avícola, Óleos Vegetais } \\
\text { Borella Ltda, Frigoplan Ltda., Sulina Alimentos S.A., } \\
\text { Ideal Avícola S.A., Frigorífico Mococa S.A.. } \\
\text { Encerramento das atividades de Curtume, venda do } \\
\text { supermercado, pomares e serrarias. Construção da } \\
\text { Perdigão da Amazônia S.A. }\end{array}$ & $\begin{array}{l}\text { Aquisições: Frigorífico Planalto S.A., Três Passos Cia. } \\
\text { Industrial de Alimentos, Corcovado Agropastoril Ltda., } \\
\text { Sudanisa Cia. Industrial de Alimentos, Comabra em } \\
\text { São Paulo, Frigorífico Mouran S.A, Abatedouro e } \\
\text { Frederco Wstphallen no Rio Grande do Sul, e } \\
\text { construção da Sadia Mato Grosso S.A. }\end{array}$ \\
\hline 1990 a 1999 & $\begin{array}{l}\text { Desativação da Perdigão Amazônia S.A., Venda da } \\
\text { Perdigão Adubos e Perdigão transportes. } \\
\text { Construção da Fabrica de Rações e da Fabrica de } \\
\text { industrializados em Marau no Rio Grande do Sul, } \\
\text { Reestruturação Societária que resultou em uma } \\
\text { única empresa de Capital Aberto a Perdigão S. A e } \\
\text { na empresa Operacional Perdigão Agroindustrial } \\
\text { S.A. }\end{array}$ & $\begin{array}{l}\text { Construção das Fabricas de salsichas em Duque de } \\
\text { Caxias, Margarinas em Paranaguá, Itapetininga, da } \\
\text { Sadia Agroavícola S.A e em Várzea Grande, } \\
\text { Abatedouro e Fabrica de Massas em Ponta Grossa, } \\
\text { Base de Distribuição em Buenos Aires, Lapa } \\
\text { Alimentos, Churrascaria Beijing Brasil em Pequim; } \\
\text { aquisições: Chapecó Avícola, Copava Indústria de } \\
\text { óleo Vegetal, Miss Daisy; Granja Rezende; } \\
\text { fechamento da Fábrica de Macarrão e moinhos na } \\
\text { Lapa e das operações de abate de bovinos. }\end{array}$ \\
\hline 2000 a 2008 & $\begin{array}{l}\text { Construção do Complexo de Rio Verde em Goiás, } \\
\text { Aquisição Frigorífico Batávia e manutenção da } \\
\text { marca Batavo, incorporação da Perdigão } \\
\text { Agroindustrial S.A. Instalação do centro de } \\
\text { atendimento em Itajaí SC, Complexo Agroindustrial } \\
\text { de Mineiros Goiás, Aquisição de Frigorífico de } \\
\text { Bovinos em Mirassol D' Oeste no Mato Grosso. } \\
\text { Aquisição da Eleva. }\end{array}$ & $\begin{array}{l}\text { Abertura de Filiais na Argentina, no Uruguai e no Chile } \\
\text { e escritórios comerciais e de representação na Itália, } \\
\text { na Inglaterra, Emirados Árabes, Japão, Paraguai e na } \\
\text { Bolívia. Novos Centros de Distribuição em Chapecó } \\
\text { (SC) e Ponta Grossa (PR). Aquisição da Só Frango } \\
\text { Produtos Alimentícios. Retomada do abate de } \\
\text { bovinos, Projeto de instalação de fábrica da Sadia em } \\
\text { Kaliningrado, na Rússia, construção da Unidade } \\
\text { Agroindustrial de Lucas do Rio Verde. Ampliação de } \\
\text { seu Porto em Paranaguá. }\end{array}$ \\
\hline
\end{tabular}

Decorridos mais de 60 anos da formação da Sadia e da Perdigão, muitas modificações ocorreram em suas estruturas, produtos, composição de capital e controle. Atualmente, ambas as empresas são de capital aberto e negociam suas ações na Bolsa de Valores de São Paulo (BOVESPA). Porém, até o processo de fusão a Sadia S.A estava sob o comando da família fundadora de Attilio Fontana, por intermédio da sua terceira geração. A Perdigão S.A, por seu turno, após a década de 80 teve seu controle acionário assumido por um consórcio de Fundo de Pensão. Os maiores acionistas da Perdigão, até então, eram o Fundo de Pensão do Banco do Brasil e a Fundação Petrobras de Seguridade Social.

No dia 19 de maio de 2009, foi anunciada a fusão das empresas e a criação da Brasil Foods (BRF), que segundo Oliveira (2009, p. 67) “[...] nasce como uma das três maiores exportadoras de alimentos do mundo, a maior empregadora brasileira com 116 mil funcionários e a $11^{\mathrm{a}}$ empresa do país em faturamento". Embora a negociação entre as empresas tenha tratamento de fusão, o que se percebe, é uma incorporação da Sadia pela Perdigão, pois a composição acionária da BRF, após a negociação, passou a ter a seguinte representação: $68 \%$ da Perdigão e 32\% da Sadia, e ainda, a BRF passou a ser a nova denominação da Perdigão S.A.

\section{Metodologia}

A metodologia aplicada na pesquisa quanto aos objetivos é descritiva, quanto aos procedimentos, caracteriza-se como bibliográfica e documental com abordagem qualitativa e quantitativa. A análise dos dados compreende o período de $1^{\circ}$ de janeiro de 1997 a 31 de dezembro de 2008 e foi desenvolvida em duas etapas. 
A primeira etapa abrange a análise de crescimento das empresas Sadia S.A. e Perdigão S.A., desenvolvida a partir dos relatórios anuais e demonstrativos financeiros das empresas. Compara-se a evolução da Receita Bruta obtida no Mercado Externo e Interno, Lucro Líquido, Ativo Total e o número de funcionários. Para obter a evolução real das empresas utilizou-se como base o ano de 1997, deflacionando os exercícios de 1998 a 2008. Na deflação foi aplicado o Índice Geral de Preços - Disponibilidade Interna (IGP-DI) da Fundação Getulio Vargas.

$\mathrm{Na}$ segunda etapa é realizada a análise do desempenho das empresas por meio de indicadores contábil-financeiros; que apresenta como objetivo estudar o desempenho financeiro de uma empresa em determinado momento passado, para diagnosticar sua posição atual e produzir resultados de tendências futuras (MARTINS, 1987). Foram analisados os indicadores de Liquidez Seca, Liquidez Corrente, Liquidez Geral, Endividamento, Margem Bruta, Margem Líquida, Rotação do Capital Próprio, Giro do Ativo, Rentabilidade do
Ativo e Rentabilidade do Patrimônio, conforme metodologia proposta por Matarazzo (2003).

Os dados necessários à análise foram obtidos junto à Base da Economática Software de Apoio a Investidores Ltda. e são expressos em moeda ajustada pela inflação, de acordo com o Índice Geral de Preços - Disponibilidade Interna (IGP-DI).

\section{Apresentação e Análise dos Resultados}

Nesta seção os dados da pesquisa, no que se refere ao crescimento e desempenho das empresas, são apresentados e analisados.

\subsection{Comparativo de Crescimento da Sadia S.A e da Perdigão S.A}

O faturamento da Sadia S.A. e da Perdigão S.A. é composto por receitas obtidas no mercado interno e no mercado externo. A evolução das mencionadas receitas é mostrada na Figura 1 , respectivamente.

\section{Figura 1 - Receita Bruta Mercado Interno e Mercado Externo}

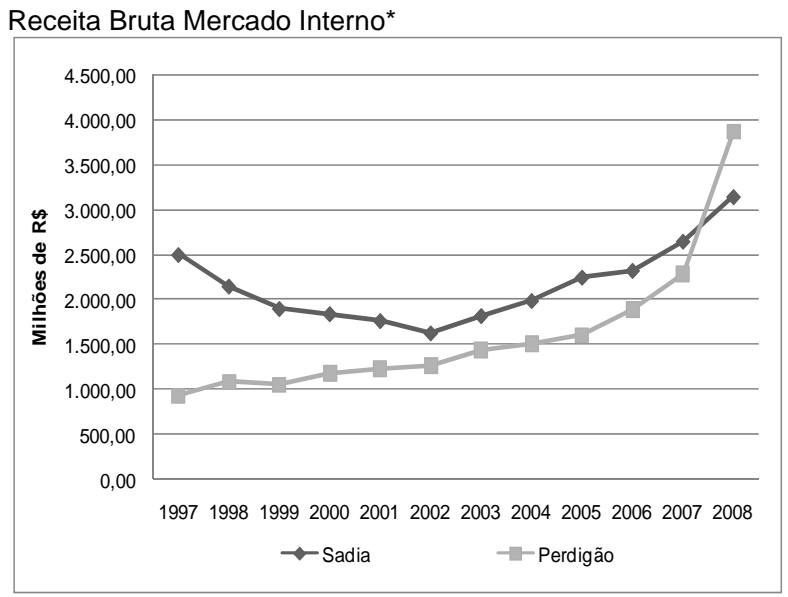

\section{Receita Bruta Mercado Externo*}

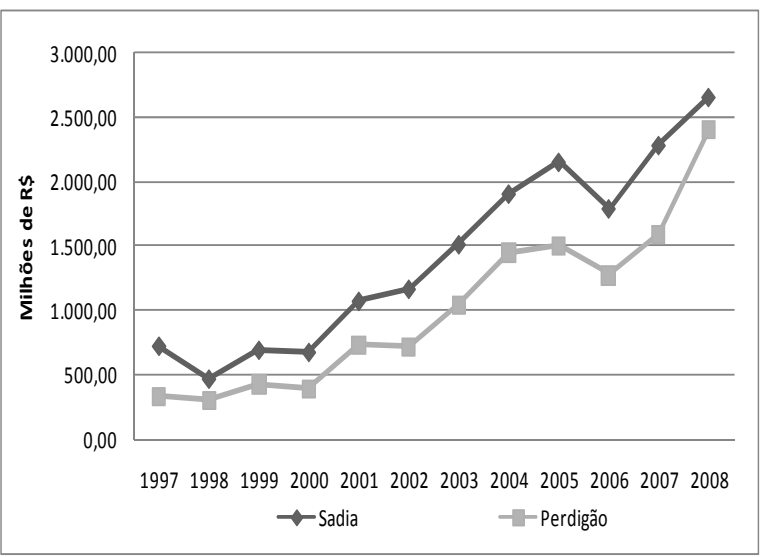

* Base IGP-DI $1997=100$

Fonte: Elaborado pelos autores com dados dos demonstrativos financeiros das empresas

Como se observa, no mercado interno a diferença entre o faturamento da Sadia e em relação ao faturamento da Perdigão apresenta decréscimo no período estudado. A Sadia após perder receita no mercado interno, de 1997 até 2002, reage a partir de 2003. Contudo, mesmo com essa evolução, o valor não foi suficiente para apresentar crescimento em termos percentuais em relação ao ano de 1997. A Perdigão, entretanto, apresentou crescimento constante de seu faturamento, e em 2008 ultrapassou, pela primeira vez, o faturamento da Sadia.
O faturamento obtido no mercado externo manteve-se semelhante. As empresas apresentaram um crescimento de 1998 até 2005, juntamente com os exercícios de 2007 e 2008. O decréscimo observado no ano de 2006, tanto da Sadia, quanto da Perdigão, estão relacionados à queda do consumo dos produtos no mercado externo, como reflexo da crise aviária, e, ainda, a valorização do real em relação ao dólar, ocorrida neste período. 
A receita bruta real da Sadia e da Perdigão, juntamente com o Lucro Líquido, são apresentados na Figura 2, respectivamente.

\section{Figura 2 - Evolução da Receita Bruta e Lucro Líquido - 1997 a 2008}

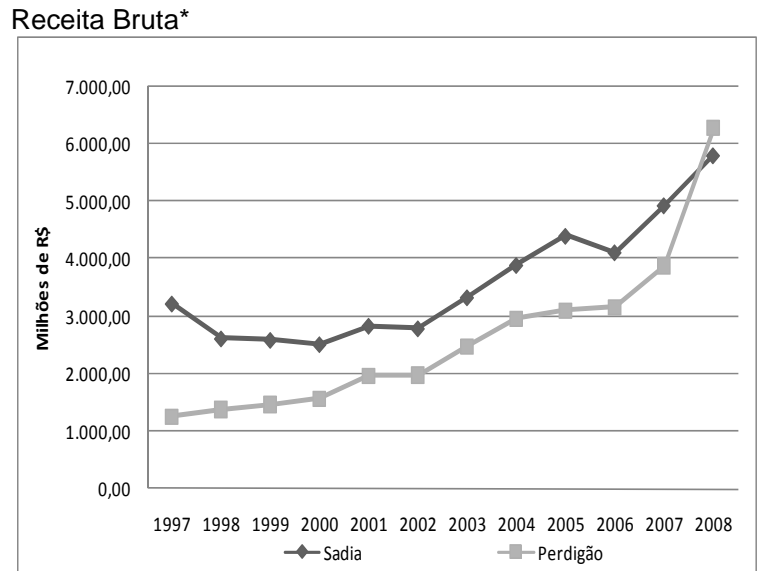

* Base IGP-DI $1997=100$

Fonte: Elaborado pelos autores com dados dos demonstrativos financeiros das empresas
Lucro Líquido*

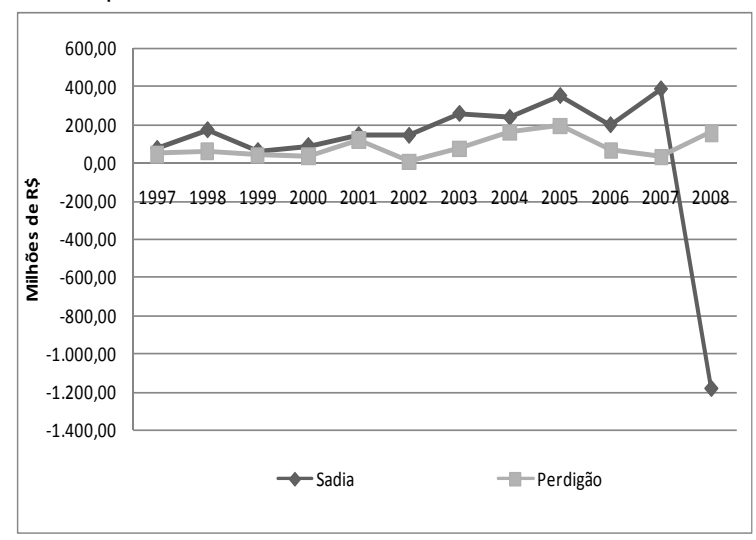

Embora o volume da receita bruta da Sadia seja superior ao da Perdigão, percentualmente, a Perdigão apresenta maior desempenho e estabilidade no crescimento. Em 1997, a Sadia faturou 3,2 bilhões e em 2008, seu faturamento deflacionado, foi de 5,8 bilhões. A Perdigão, por seu turno, obteve um faturamento de 1,2 bilhões em 1997, passando para 6,2 bilhões, em 2008. Em termos percentuais, o faturamento bruto da Sadia cresceu $80 \%$, enquanto a Perdigão apresentou um crescimento real de 394\%, no período de 1997 a 2008.

Apesar de a Sadia e a Perdigão apresentarem estabilidade em termos de crescimento de seu faturamento, de forma geral, em relação aos resultados, essa realidade não se confirma. Este fato pode estar relacionado a especificidades da área, como o custo da matéria-prima, pois as oscilações apresentam movimentos semelhantes. Pode-se observar, ainda, que no exercício de 2008, como reflexo da crise internacional e das estratégias de financiamento, a Sadia S.A. apresenta um prejuízo histórico, e por conseqüência, o desempenho mais deficitário da série. Importante destacar que, apesar de o resultado do exercício ser expressivamente deficitário, o volume de receitas da empresa não foi atingido pela crise, e, por conseqüência, o seu desempenho operacional.

A Figura 3 mostra a evolução do Ativo Total e do número de funcionários, respectivamente.

Nova semelhança é observada em relação à evolução do Ativo Total. A Sadia possuía, em 1997 e 2008, um ativo total de 2 bilhões e 6,5 bilhões, respectivamente, representando um crescimento de 224\%. O ativo da Perdigão em 1997 somava 1,2 bilhões e em 2008 passou a representar 5,3 bilhões, um crescimento de 331\%, no período.

A evolução do número de funcionários confirma a grande competitividade das empresas. Em 1997 a Sadia empregava 25.375 colaboradores, em 2008 esse número passou a ser de 60.580, um acréscimo de 139\%. A Perdigão, nesse mesmo período, apresentou um aumento de 14.353 colaboradores para 59.008, um aumento de $311 \%$. 
Figura 3 - Ativo Total e Número de Funcionários - 1997 a 2008

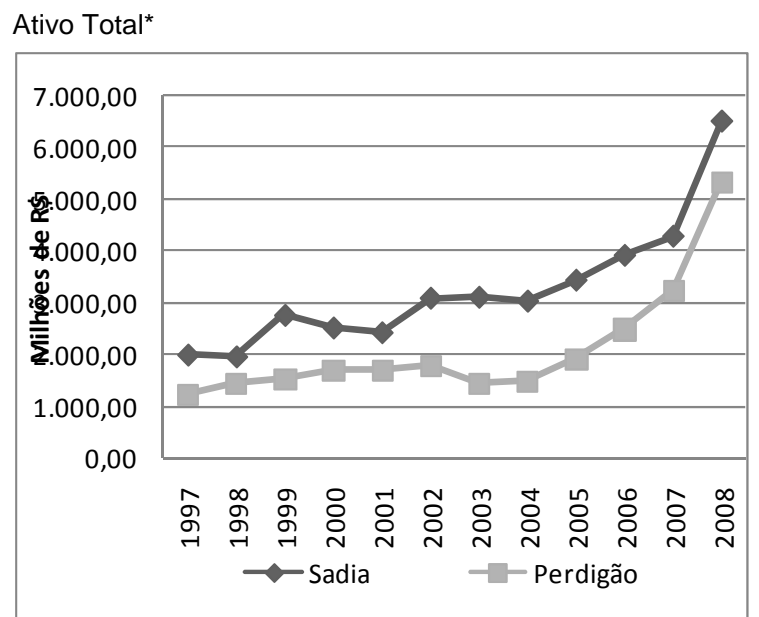

\section{Número de Funcionários}

* Base IGP-DI $1997=100$

Fonte: Elaborado pelos autores com dados das empresas

\subsection{Análise de Desempenho}

A análise de desempenho pode ser entendida como um processo de quantificação da eficiência e eficácia em relação às decisões tomadas por determinada corporação. Neste sentido, o desempenho das empresas Sadia S.A. e Perdigão
S.A. é realizado por meio de indicadores contábilfinanceiros.

$\mathrm{Na}$ Figura 4 a evolução dos indicadores de Liquidez Seca e Liquidez Corrente, são apresentados.

\section{Figura 4 - Liquidez Seca e Liquidez Corrente}
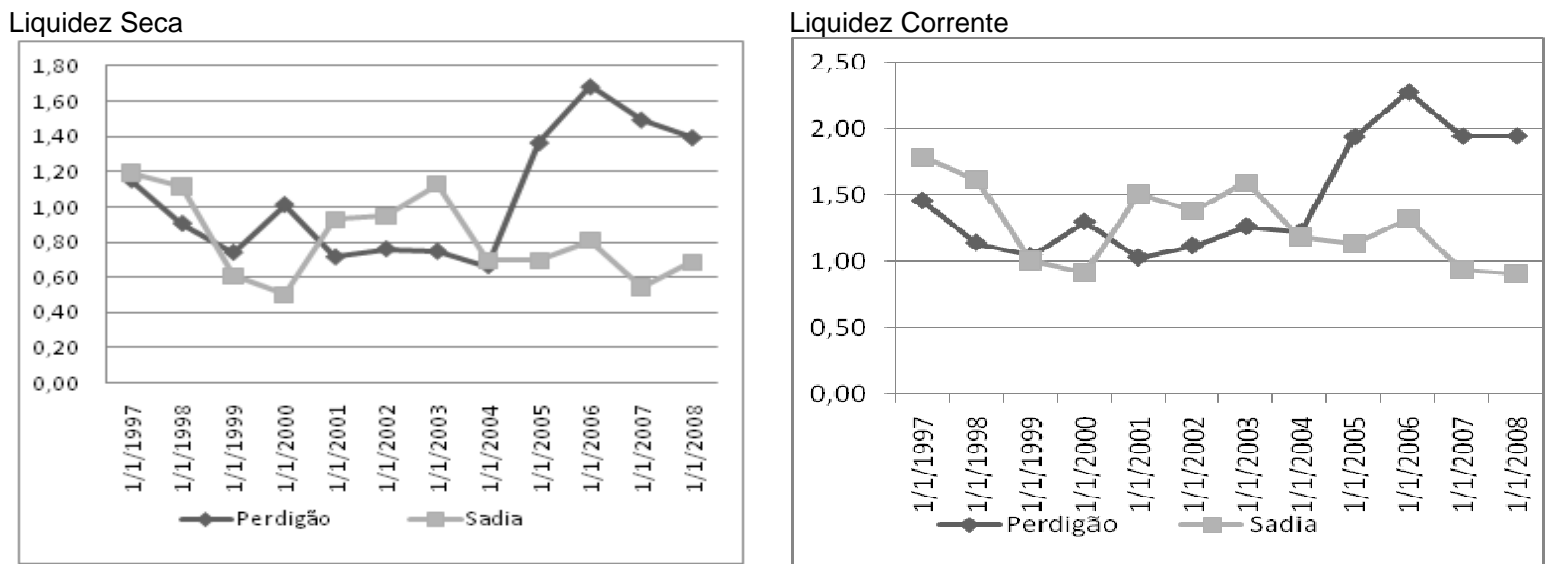

Fonte: Elaborado pelos autores com dados dos demonstrativos financeiros das empresas

Como se observa apesar de as empresas Sadia e Perdigão apresentarem oscilações em suas capacidades de pagamento de curto prazo, a Perdigão mostrou melhor Liquidez, especialmente a partir do exercício de 2004.
A Figura 5 mostra a evolução dos indicadores de Liquidez Geral e Endividamento Geral, respectivamente. 
Figura 5 - Liquidez Geral e Endividamento
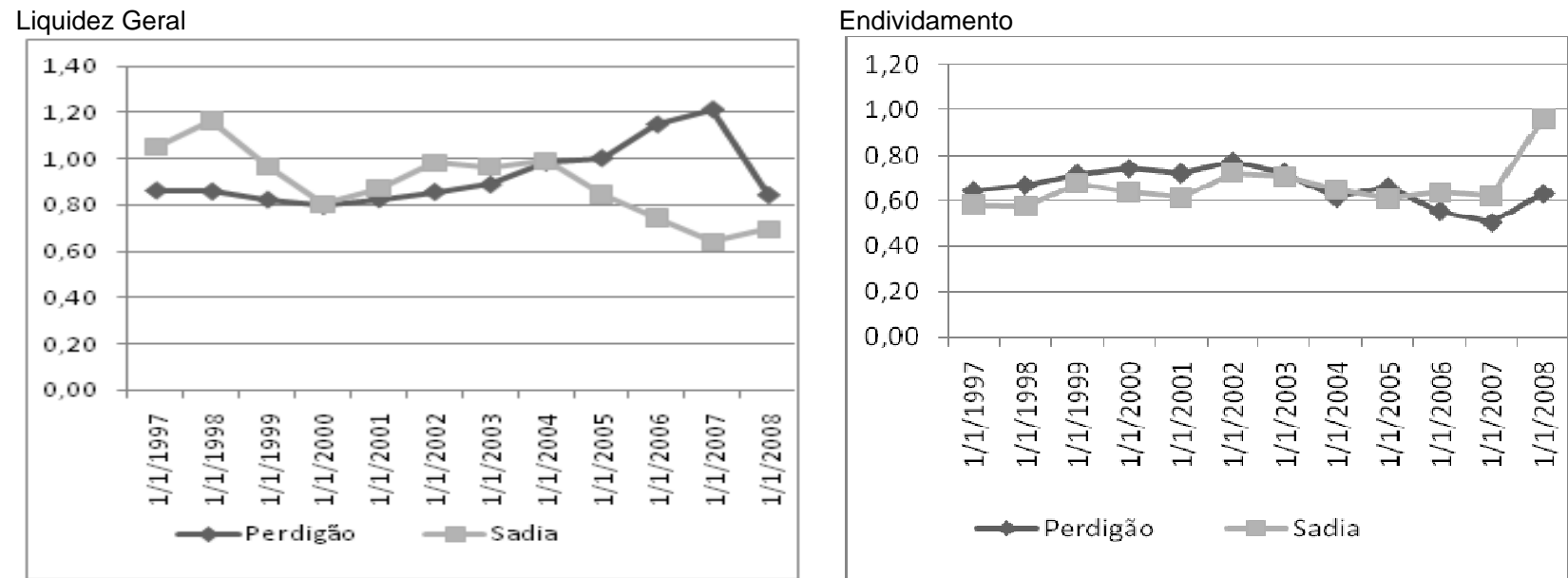

Fonte: Elaborado pelos autores com dados dos demonstrativos financeiros das empresas

Embora a Perdigão, em 2008, apresente queda de sua capacidade de pagamento de longo prazo, pode-se afirmar que a empresa possui uma boa liquidez geral (80\%). Percebe-se ainda, que apesar de a Sadia apresentar declínio gradativo do referido indicador, os resultados das duas empresas se assemelham. Em relação ao indicador de
Endividamento, a Sadia apresentou no exercício de 2008, um comprometimento de seu ativo total de $97 \%$ para com terceiros, mostrando aqui os impactos dos resultados deficitários sofridos no mencionado exercício. A Figura 6 mostra a evolução dos indicadores de Margem Bruta e Margem Líquida, respectivamente.

Figura 6 - Margem Bruta e Margem Líquida
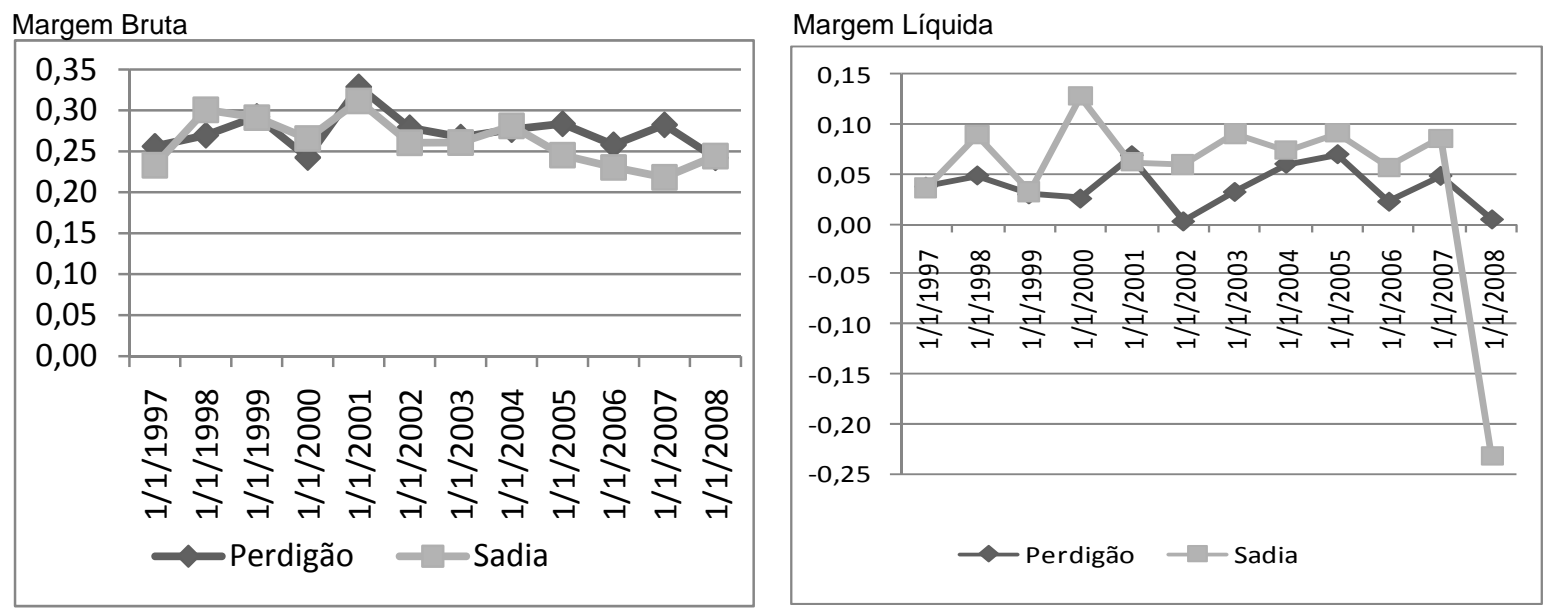

Fonte: Elaborado pelos autores com dados dos demonstrativos financeiros das empresas

A Margem Bruta, que é a parcela das receitas líquidas, após deduzidos os custos de produção, que resta para a dar cobertura as demais despesas, apesenta-se uniforme nas duas empresas, confirmando que as estratégias de preços e custos da Sadia e da Perdigão, novamente se assemelham.

Entretanto, a análise da Margem Líquida, torna evidente que a Sadia sempre manteve o referido indicador mais elevado que sua, até então, concorrente direta. Exceção feita ao exercício de 2008, em que a Sadia somou mais do que 3,5 bilhões de reais de despesas financeiras (operações com derivativos), e, por consequência, um resultado deficitário de aproximadamente 2,5 bilhões de reais. A Perdigão, por seu turno, apesar de sofrer os impactos de um ano totalmente atípico, continuou a apresentar resultado positivo. 
A Figura 7 apresenta a evolução dos do Ativo, respectivamente. indicadores de Rotação do Capital Próprio e Giro

\section{Figura 7 - Rotação do Capital Próprio e Giro do Ativo}
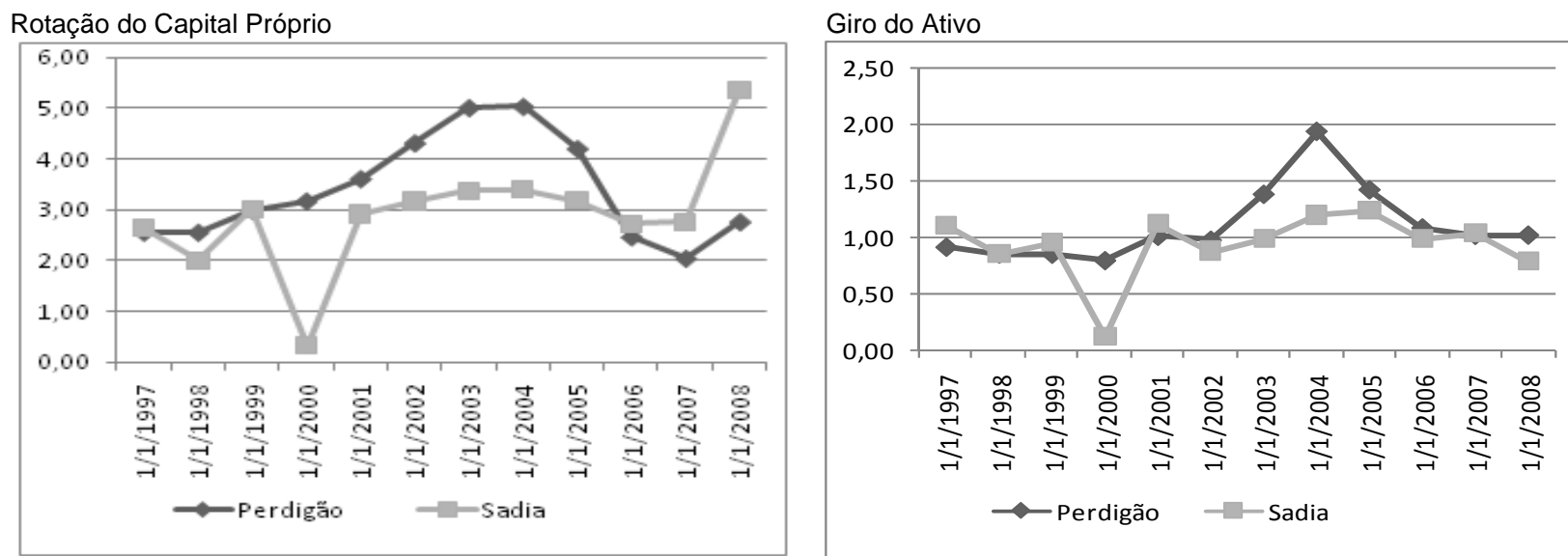

Fonte: Elaborado pelos autores com dados dos demonstrativos financeiros das empresas

Como se observa, com exceção do exercício de 2000, ano em que a Sadia apresenta expressiva queda na capacidade de geração de receita em relação ao seu capital próprio, as empresas apresentam a mesma tendência, apesar de a Perdigão mostrar maior eficiência. $O$ fato de a Sadia, no exercício de 2008, apresentar rotação de seu capital próprio acima de 500\%, está relacionado ao resultado deficitário deste período, cujo prejuízo absorveu praticamente todo o seu Patrimônio Líquido.
Em relação ao Giro do Ativo, que explica a capacidade de geração de receita por meio dos investimentos totais, novamente é percebido a mesma tendência nas empresas e mellhor desempenho para a Perdigão.

A Figura 9 mostra a evolução da Rentabilidade do Ativo e a Rentabilidade do Patrimônio Líquido, respectivamente.

\section{Figura 9 - Rentabilidade do Ativo e Rentabilidade do Patrimônio Líquido}
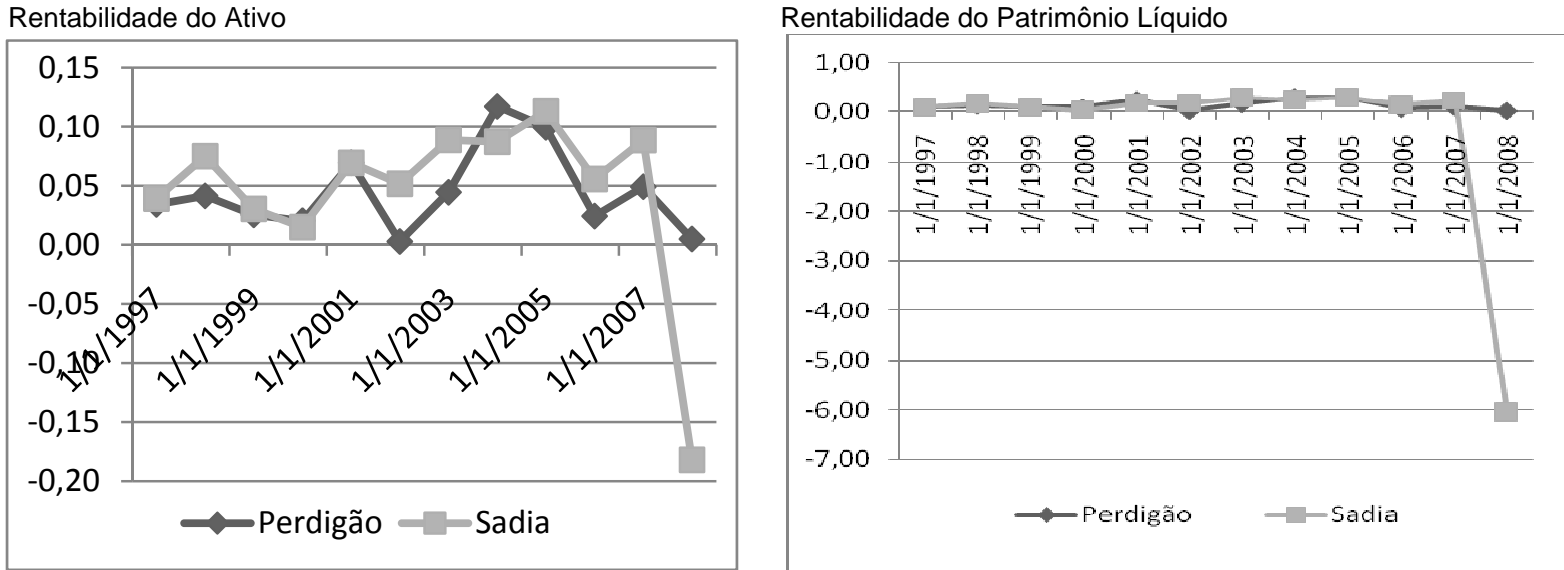

Fonte: Elaborado pelos autores com dados dos demonstrativos financeiros das empresas

A Sadia e a Perdigão, exceção feita ao exercício de 2008, durante mais de uma década apresentaram a mesma tendência oscilatória de Rentabilidade do Ativo e praticamente o mesmo percentual de Rentabilidade do Patrimônio Líquido, comprovando assim, a grande competitividade que existiu entre essas empresas durante as suas trajetórias históricas. 


\section{Considerações Finais}

O objetivo desse estudo consistiu em apresentar o processo de formação e crescimento da Sadia S.A. e Perdigão S.A., juntamente como os seus desempenhos, medidos por indicadores contábilfinanceiros no período que antecedeu o processo de fusão dos grupos.

Os dados da pesquisa indicam que, após a transferência de seu controle acionário e reestruturação administrativa, a Perdigão ganha gradativamente maior estabilidade, especialmente no mercado interno, ao contrário dos resultados demonstrados pela Sadia, que no mercado interno apresentou maior instabilidade até o ano de 2002. Os dados da evolução das empresas permitiram observar ainda, que as companhias evoluíram positivamente em termos de faturamento total, contudo os seus resultados líquidos apresentam instabilidades e variaram praticamente na mesma proporção até o exercício de 2008, ano em a Sadia apresentou resultado altamente deficitário, com reflexos da crise internacional.

Apesar de a união dos grupos Sadia e Perdigão ser considerada como fusão, o que se percebe de fato, é a incorporação da Sadia S.A. pela Perdigão S.A.. Este fato pode estar relacionado à melhor eficiência nos resultados da Perdigão nos últimos anos, e em especial, por uma estratégia de financiamento da Sadia, que com os impactos da crise internacional de 2008, atingiu fortemente as despesas financeiras da empresa, e, por consequência, desestabilizou os seus resultados no exercício de 2008.

Cumpre ressaltar que, potencialmente, a Sadia poderia recuperar-se das consequências do resultado deficitário, no entanto, as estratégias de crescimento e ganhos em escala da união dos grupos, somados ao prejuízo da Sadia em 2008, foram fatores fundamentais para a criação da Brasil Foods S.A., que ganha em competitividade e crescimento, especialmente no mercado externo.

Por fim, destaca-se que a Sadia e a Perdigão expandiram suas atividades nas primeiras décadas de forma diferenciadas, mas ao longo dos anos trilharam caminhos semelhantes. A grande competitividade que acompanhou a trajetória histórica dessas duas empresas encerra-se com a fusão dos grupos. Começa aqui uma nova etapa de expansão, especialmente no mercado externo, com a criação da Brasil Foods S.A., empresa que nasce como uma das grandes potências brasileiras no mercado mundial.

Como limitação da pesquisa, destaca-se que a análise do comparativo histórico das empresas Sadia e Perdigão, foi construída a partir de informações secundárias, disponibilizadas pelas próprias empresas em seus respectivos sítios e por demais pesquisas da área. E, ainda, que a pesquisa não apresenta como objetivo apontar quais foram os principais fatores que contribuíram para o processo de fusão dos grupos, mas, em caracterizar o contexto histórico que antecedeu este processo.

Para futuras pesquisas, sugere-se maior profundidade nos fatores que contribuíram para o processo de fusão dos grupos, por meio de pesquisas empíricas, como entrevistas e coleta de dados junto aos administradores das empresas. Sugere-se, ainda, pesquisas que avaliem os impactos do processo de fusão dos grupos, no que se refere ao desempenho e crescimento a partir do exercício de 2009.

\section{Referências}

CHANDLER JR., A. D. Scale and scope: the dynamics of industrial capitalism. Massachusetts: Harvard University Press, 1990.

Gestão dos herdeiros ou de profissionais na empresas familiares: o caso da Perdigão.

Revista de Economia Contemporânea, v. 11, p. 197-225, 2007.

MARTINS, E. ASSAF NETO, A. Administração

financeira: as finanças das empresas sob condições inflacionárias. São Paulo: Atlas. 1987.

MATARAZZO, D. C. Análise financeira de balanços. 6. ed. São Paulo: Atlas, 2003.

OLIVEIRA, D. Troca de papéis. Época Negócios, ano 3, n. 28, jun. 2009.

PENROSE, E. T. The theory of the growth of the firm. Basil Blackwell, Oxford, 1959.

PERDIGÃO S.A. Homepage. Disponíveis em: http://<www.perdigão.com.br>. Acesso em julho de 2009.

SADIA S.A. Homepage. Disponível em: http://<www.sadia.com.br>. Acesso em: julho de 2009. 